\section{Losing your mind}

\section{Tim Jacob}

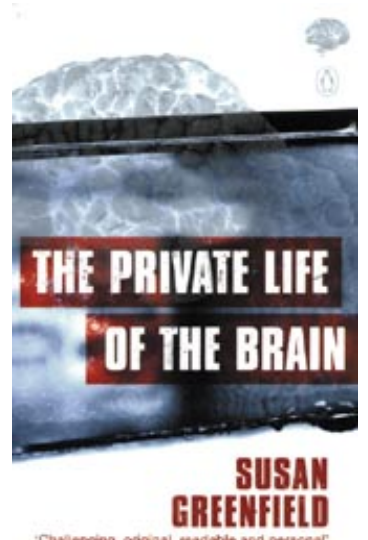

The Private Life of the Brain

by Susan Greenfield

Penguin Books, London, UK

272 pages, €9.70

ISBN 014024914

The mind is separate from consciousness, but is indistinguishable from 'self'. So says Baroness Susan Greenfield in her new book, in which she explores these two entities and attempts to define the relationship between them. Indeed, what was once the sole preserve of philosophers, priests and poets is increasingly being invaded by men and women armed with electrodes, determined to have their say. But will emotions and self-awareness really give up their secrets to this kind of investigation?

Greenfield maintains that consciousness is an emergent property of the whole brain and that emotion cannot be separated from it. Emotion is not an occasional and different brain state but is with us all the time. Central to her thesis is that the more we are feeling emotional, the less we are accessing our individual minds, the less we are being ourselves.

Consciousness is a property of human brains, and necessary for understanding. Initially a child does not have selfawareness, it lives in an emotional world. Children are passive victims of their senses, the exaggerated impact of external stimuli being due to the absence of a developed internal mind or a collection of experiences by which to interpret sensory input. By the age of two, many neuronal networks have been established and the child learns to use language. At four they begin to realise their thoughts are unique. The distinction between internal and external becomes established and the formation of an individual self is complete.

It is this complexity of the brain that Greenfield claims is lost when people literally 'blow their minds' on drugs, so basically both emotions and drugs are an abandonment of the mind. Recreational drugs are taken presumably to have some pleasurable effect and thus pleasure is equated with a loss of mind, or a reduction in the number of active neuronal networks. She proceeds to describe how past and present recreational drugs could lead to a lessening of neuronal activitypredisposing the mind to a greater experience of pleasure. It is difficult to go along with this at times, especially when considering such disparate drugs as opium and amphetamines. The grouping together of strange bedfellows continues as Greenfield explains how she links pleasure and fear-fear is pleasure happening a bit too fast. For both emotions, she suggests, high levels of dopamine operating from the prefrontal cortex enable a ready aggregation of neuronal networks, and whether pleasure or fear occurs depends upon the rapidity of novel external stimuli.

At the other end of the scale, overactive neuronal networks result in depression and the potential for the experience of pain. She argues that pain and depression are closely related and both involve a shift of attention from the sensual outside world to the inner mind. She proposes a novel-and I have to say outrageousidea that pain might have evolved to shift consciousness from excessive neuronal networking, to a less busy brain where we can get on with the important business of feeding and copulation.

All this doesn't sound very encouraging-lose your mind and feel pleasure, use it and suffer depression. But there is hope. By meditation, Buddhists achieve a consciousness where the inner resources are so extensively developed that they saturate their neuronal interactions. Theirs is the ultimate neuronal constellation by which they experience a total loss of all emotion but achieve wisdom.

It is not until Chapter 7 that we learn that no current theory of emotions can yet account for the ability of words to stir the whole body into a turmoil of feeling. This does not deter Baroness Greenfield from developing an elaborate, and at times very speculative, account of how the brain experiences emotions, pain, fear, depression and pleasure. But her theory cannot explain the potential of words to stir the heart.

Greenfield really does believe that by delving into the cellular activity of the brain we will find the neuronal substrate for consciousness and understand how the mind colours the way we feel. However, she struggles to pinpoint the exact moment of emergence of consciousness in humans and at what point in the animal kingdom consciousness can be said to be present. We return to a familiar problem-the very definition of consciousness, which she evades by saying that it is a continuum. But it is difficult to imagine self-awareness, the consciousness of being conscious, increasing little by little as we rise up through the animal kingdom until fully fledged, self-reflective thought is manifested in humans.

At the end of the book Greenfield summons the courage to present her definition of consciousness, which, for my taste, begs more questions than it solves. Much speculation from Greenfield is a result of a kind of deductive logic so beloved of Oxford academics. In such arguments the proponents can, after seemingly faultless logical steps, end up justifying some very strange propositions. All of which is fine since it stimulates debate, and to her credit, Greenfield is obviously at great pains to present us with a falsifiable hypothesis. And the inevitable future developments in brain imaging technology will allow her hypothesis to be tested.

The author is at the School of Biosciences, Cardiff University, Cardiff, UK.

E-mail: jacob@cardiff.ac.uk

DOI: $10.1093 /$ embo-reports/kvf046 